\title{
Sex and the scope
}

\author{
Winnie Wong MD¹, Paul C Adams MD², Editor-in-Chief
}

$\mathrm{W}$

innie Wong is an Associate Professor of Medicine in the Division of Gastroenterology at the University of Alberta, Edmonton, Alberta. She chaired a session at the World Congress of Gastroenterology in Montreal, Quebec, with an international speaking faculty, looking at global issues and differences facing women in gastroenterology. She is also the Chair of the Gender Committee of the Canadian Association of Gastroenterology (CAG).

PA: Can you describe the current playing field for women in gastroenterology and hepatology in Canada?

WW: According to CAG data on its membership, as of 2004, women comprise $22 \%$ of regular members and $42 \%$ of trainee members. However, there is no breakdown in terms of practice interest (gastroenterology versus hepatology) or MDs versus PhDs. When separated by province, percentage of female membership differs widely, from $6 \%$ in Saskatchewan to $50 \%$ in Prince Edward Island. When only provinces with more than 20 respondents are considered, Alberta has the highest percentage of women members at $37 \%$. A recent survey

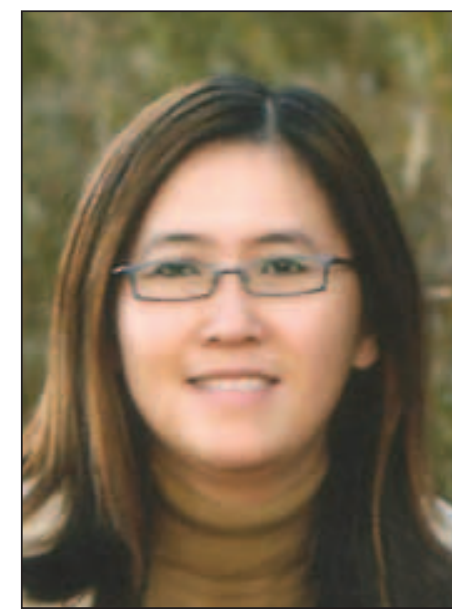

Dr Winnie Wong is an Associate Professor of Medicine in the Division of Gastroenterology at the University of Alberta in Edmonton, Alberta
Gastroenterology Residents in Training course (at that time known as the CAG Fellows Course), the impressive roster of women in executive positions, such as Drs Suzanne Lemire (CAG President), Eve Roberts and Jenny Heathcote. However, a survey across the country would likely still indicate that women comprise a disproportionate minority in the upper echelon of academic medicine.

PA: Can these issues be overcome by modifying existing program structures?

WW: I think so, in the following ways. At the University of Alberta, we frequently have the same struggle in terms of trying to de-emphasize the 'technical' aspect of endoscopy, to redirect back to the more important 'cognitive' aspect of our specialty. I believe that this is important not only in attracting women to the specialty, but more importantly, to attract bright thinkers to gastroenterology and hepatology (3). Although the exact reasons for the higher percentage of women in certain provinces, such as Alberta, is not known, it is widely believed that this may be a result of women role models and mentors. However, I must say that I am not a firm believer that women can from CAG suggested that only $12 \%$ of Canadian gastroenterologists were women. A survey from Asia showed that the mean percentage of female gastroenterologists is $27.4 \%$ at the respective gastroenterology societies (China, India, Japan, Malaysia, Taiwan, Thailand and Myanmar). In South America, women represent $18 \%$ of 7424 gastroenterologists.

PA: Why are fewer women choosing a career in gastroenterology compared with other specialties?

WW: There is substantial evidence to support this observation. Gastroenterology is perceived as being a procedure-oriented specialty, which traditionally has attracted men more than women. With the procedures comes a lifestyle which involves calls and performing urgent/emergent procedures at night. Gastroenterology rotations for the junior (general internal medicine) residents frequently involve a lot of observing procedures. This de-emphasis of the cognitive aspect of our specialty may contribute to fewer women being interested in gastroenterology $(1,2)$. Mentors or role models have been frequently cited as a major factor for women in their career choice, perhaps much more so than for men. I think that in Canada, we have actually been very progressive in terms of having women in executive and visible positions. I can recall, as an internal medicine resident attending the first ever only learn from women mentors or role models. I think that while certain lifestyle and biological issues may be genderspecific, the fundamental and intrinsic qualities of what makes a great mentor is genderless. To this end, I think that it is vital for gastroenterologists and hepatologists (of either sex) to actively scout for 'talent' in medical schools and internal medicine programs, and to actively foster a mentor-mentee relationship with these individuals to show them the fantastic and exciting opportunities that this specialty has to offer. In terms of the busy gastroenterology lifestyle, I don't think that modifications can be made in the training program (ie, at the end of the day, you still need to have performed a certain number of procedures to attain competence). However, this aspect can certainly be addressed by ongoing growth to our specialty, which eventually will result in lower call frequency.

PA: Are the systems in place for maternity leave satisfactory at the present time?

WW: In Canada, I believe that at the residency level, it is on par with other occupations, but I believe that this is programspecific. For example, in our own program, we have had residents/fellows take either a six-month or 12-month maternity leave (depending on their choice and financial needs). In academic departments, I also believe that this is institution-specific,

${ }^{1}$ Division of Gastroenterology, University of Alberta, Edmonton, Alberta; ${ }^{2}$ London Health Sciences Centre, London, Ontario

Correspondence: Dr Winnie Wong, Division of Gastroenterology, University of Alberta, 1-10 Zeidler/Ledcor Centre, 130 University Campus,

Edmonton, Alberta T6G 2X8. Telephone 780-492-8134, fax 780-492-1600, e-mail winnie.wong@ualberta.ca 
and depends on the reimbursement structure (fee-for-service versus alternate reimbursement plans).

I am not sure about other scientific funding agencies, but the Alberta Heritage Foundation for Medical Research does have in place provisions for grant extensions for maternity leave in their operating grants. Although women can take maternity leave for variable lengths of time, I think that most still believe that a significant leave of absence is ultimately detrimental to their academic promotional process and scientific productivity. A 2001 editorial on gender equity in Gastroenterology (4) sums it up well: "It would be difficult for any scientist to take off 6 months or a year without a negative impact on their future career". Job sharing in the academic community is still not widely available.

I have recently witnessed the difficult choice of female trainees between academic and community careers, and these factors are present and very real. They need to be addressed if we are to attract bright women in academia and research.

As for community practice, I think that the issue of job sharing or locums are more feasible and widely practiced, but this comes with significant financial implications.

PA: Do woman lose out in the current promotion systems at universities? Is that why there are so few full professors in gastroenterology/hepatology?

WW: I think that there are several reasons for the disproportionately low percentage of full professors. First, although medical school classes have been more than 50\% women for several years, it takes time to grow this crop into senior positions. Second, although women can take maternity leave, they may still be expected to present for promotion at the sixth or seventh year, as calculated from the year of appointment. Third, academia lifestyle is perceived as being very time consuming, and this will directly compete with home life (5). Last, this problem is perpetuated with lack of senior female role models, leading to fewer women wanting to consider this option.

PA: Are there more women interested in hepatology compared with gastroenterology? There are many famous women role models in hepatology, such as Sheila Sherlock, Teresa Wright, Anna Lok and Jenny Heathcote.
WW: Many others have made this observation, but I don't have Canadian data to support this trend.

PA: Is male chauvinism more dominant in gastroenterology? It has been considered a specialty with similarities to surgery.

WW: I have never experienced or been apprised on any chauvinism. I am the lone female member in a division of 13 , and have never been subjected to male chauvinism. Perhaps Edmonton men are more progressive and SNAGs (sensitive new-age guys). It is interesting that Dr Lund's editorial in Gastroenterology (4) points out that most women appear to enter academia feeling that sex disparity does not exist! Perhaps my response reflects that I just haven't been in the profession long enough yet!

PA: Do female gastroenterologists attract female patients? Is that ideal?

WW: I think that there is good evidence to support the concept that female patients prefer female physicians. It is interesting that in the last CAG surveys, female gastroenterologists do not think that they are better with women patients than their male counterparts.

PA: Do you see the scene changing over time?

WW: The scene is changing, as evidenced by the CAG membership data, with $22 \%$ regular members versus $42 \%$ trainee members being women. We need to convert some of these women into leadership and research positions.

\section{REFERENCES}

1. Burke C, Sastri S, Jacobsen G, Arlow F, Karlstadt R, Raymond P. Gender disparity in the practice of gastroenterology: The first 5 years of a career. Am J Gastroenterol 2005;100:259-64.

2. Liu JJ. Gender differences in gastroenterology. Am J Gastroenterol 2005; 100:257-8.

3. Thomson AB, Enns R, Depew B, Flook N. Beyond the scope of conflict of interest. Can J Gastroenterol 2005;19:75-9.

4. Lund PK. Gender equity in biomedical science: Comments from a lone female associate editor. Gastroenterology 2001;121:243-4.

5. Woodward C, Hurley J. Comparison of activity level and service intensity of male and female physicians in five fields of medicine in Ontario. CMAJ 1995;153:1097-106. 


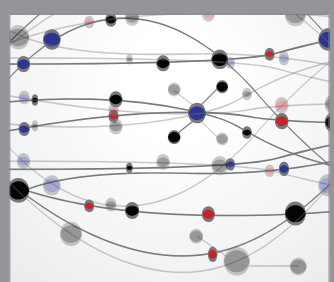

The Scientific World Journal
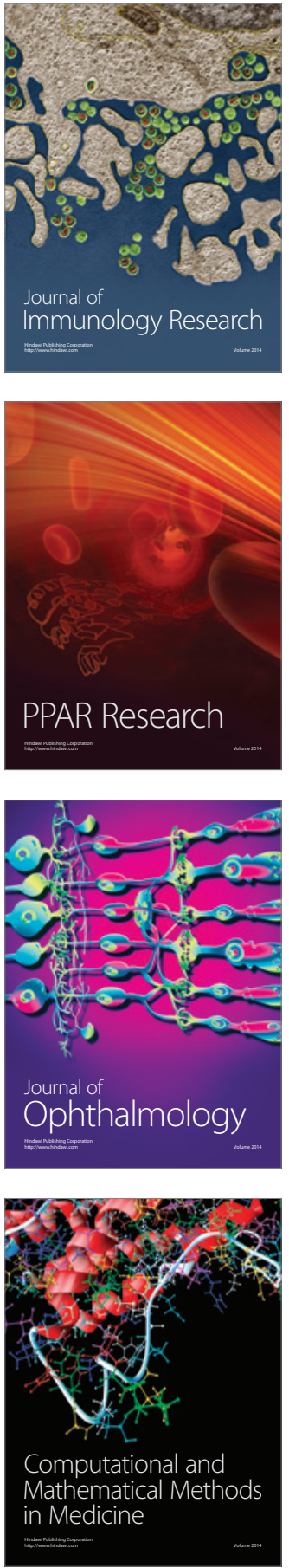

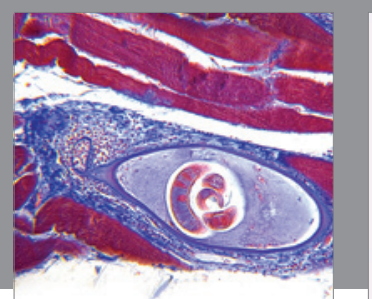

Gastroenterology Research and Practice

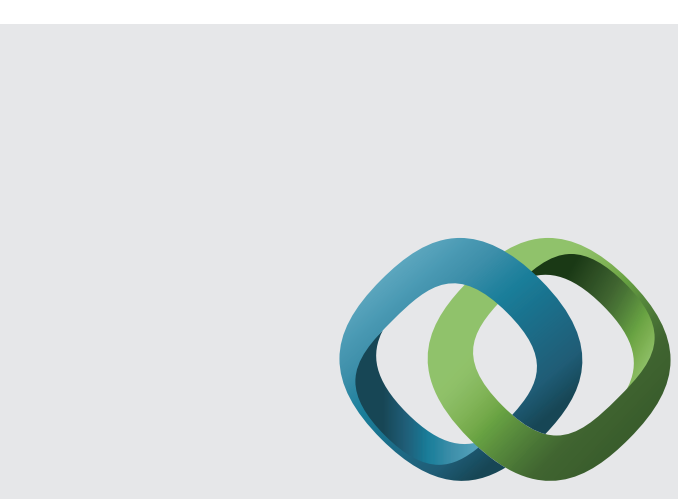

\section{Hindawi}

Submit your manuscripts at

http://www.hindawi.com
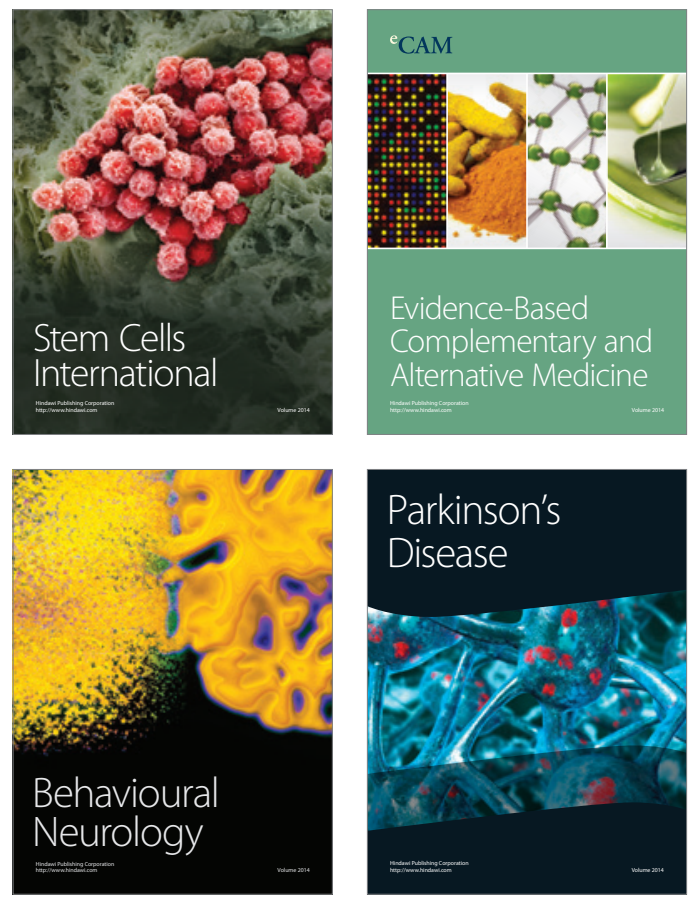
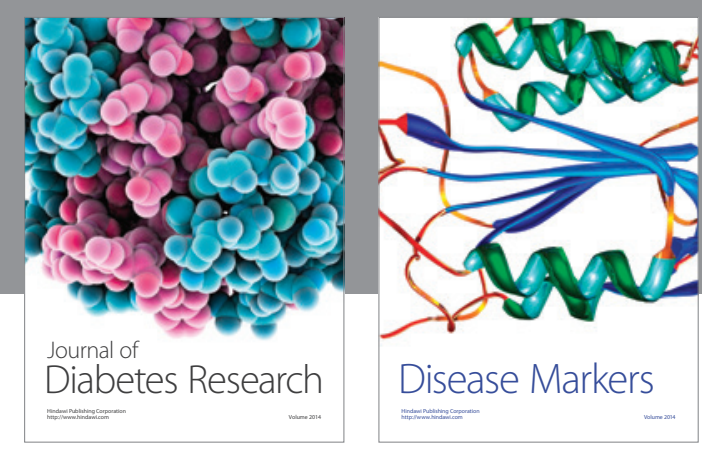

Disease Markers
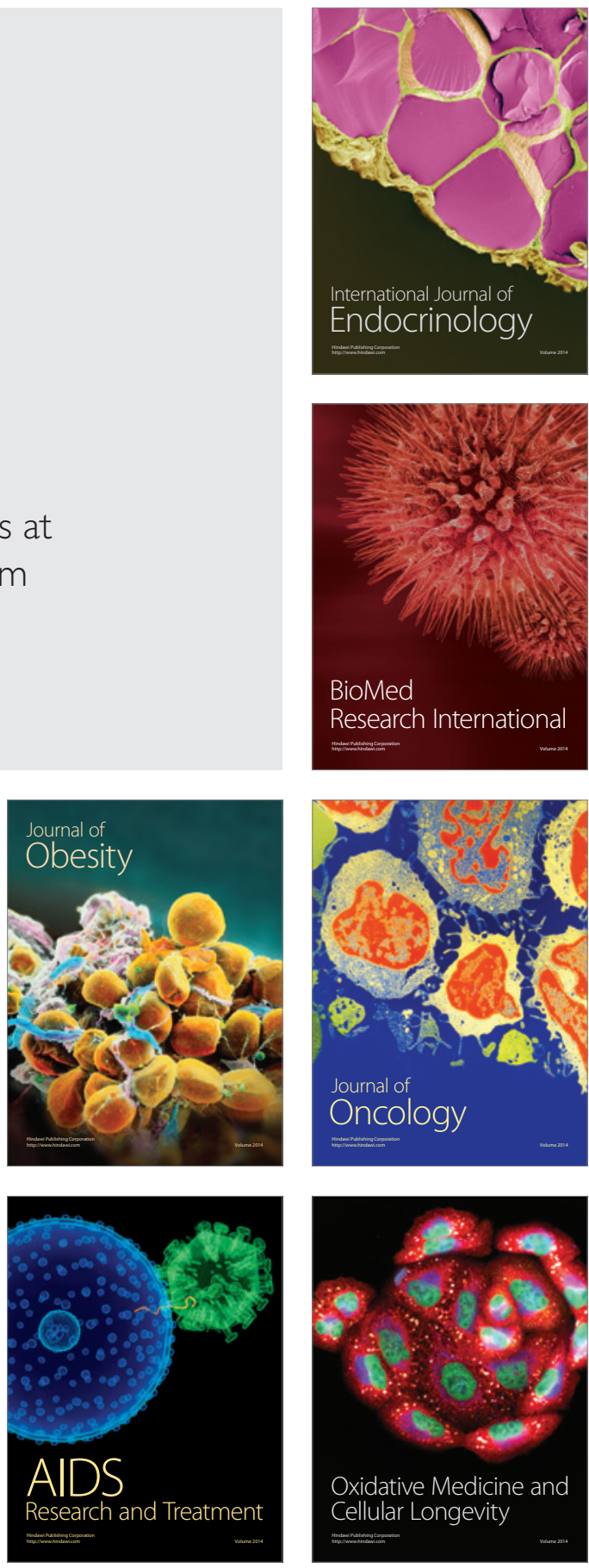